\title{
A Case of Behçet's Syndrome With Esophageal Involvement Treated With Salicylazosulfapyridine and Prednisolone
}

A 30-year-old woman was admitted with burning retrosternal pain on swallowing. She had a 16-year history of recurrent oral aphthous ulcers, genital ulcers, and erythema nodosum-like eruptions over the back. Esophagoscopy revealed multiple shallow oval ulcers in the middle esophagus with distinct but edematous margins (Figure 1). Biopsy specimens from the lesions showed only non-specific inflammatory changes. Colonoscopy revealed deep punched-out ulcers in the terminal ileum (Figure 2). We considered a diagnosis of definite Behçet's syndrome with esophageal and intestinal involvement. Prednisolone ( $40 \mathrm{mg} /$ day) was administered for eight weeks with no improvement in these ulcers; at that point oral salicylazosulfapyridine (SASP,

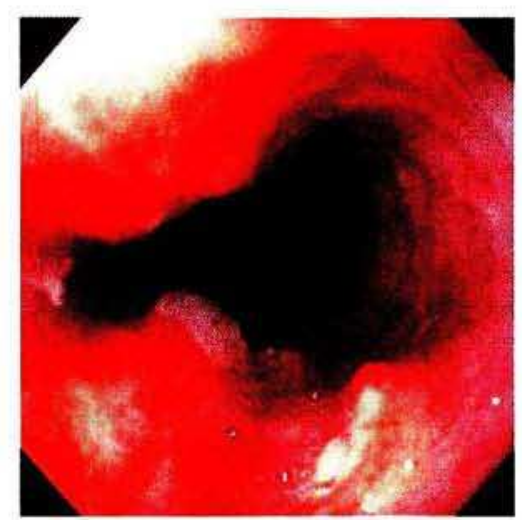

Figure 1: Endoscopic appearance of the midesophagus before treatment, showing shallow oval ulcers.
$3 \mathrm{~g} /$ day) was added to the treatment. By four weeks after initiation of SASP the burning pain on swallowing had disappeared, and subsequent endoscopy revealed complete healing of the esophageal ulcers (Figure 3). Nevertheless, the ileal ulcers did not improve.

Behçet's syndrome is an inflammatory disorder which may involve the gastrointestinal system (1). However, esophageal involvement is very rare (2-4), with only 18 definite reported occurrences to date. In our patient, the esophageal ulcers did not improve with steroid administration alone and healing was attributed to the addition of SASP. However, the ulcers in the terminal ileum were resistant to the combi-

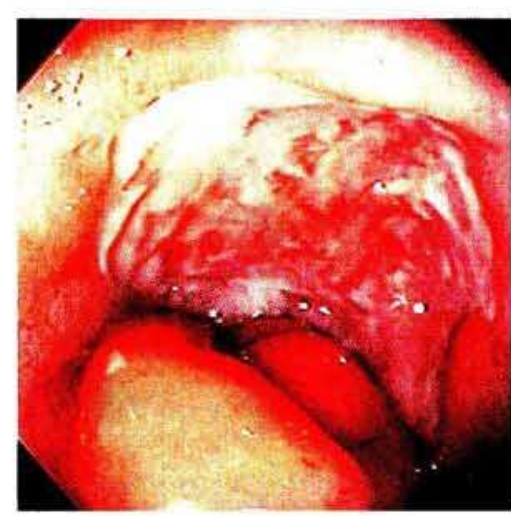

Figure 2: Endoscopic appearance of the terminal ileum, showing an extensive deep ulcer. 


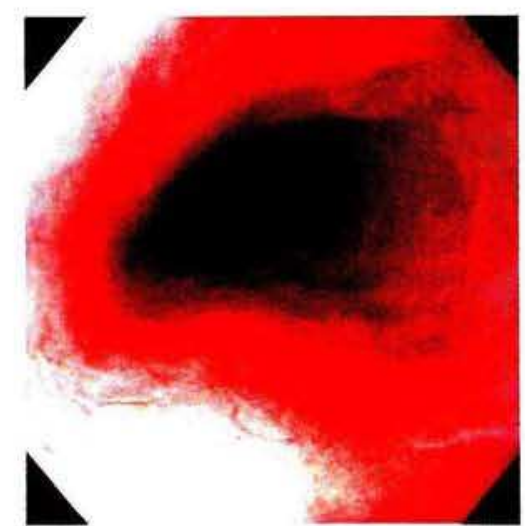

Figure 3: Endoscopic appearance of the midesophagus, showing ulcer healing after treatment.

nation therapy. Ileal lesions with Behçet's syndrome usually appear as deep punchedout ulcers (5). We speculated that the differences in therapeutic response between the esophagus and ileum may reflect the depth of the ulcers. Why ulcerations should be more shallow in the esophagus than in the ileocecum in Behçet's disease is unclear. The findings in the present case suggest that combination therapy with SASP and prednisolone may be particularly effective against esophageal involvement. As the likelihood of recurrence despite combination therapy is unclear, patients with this type of Behçet's disease require careful follow-up.

K. Ikezawa', H. Kashimura', M. Hassan², A. Nakahara ${ }^{2}$, A. Yanaka ${ }^{2}$, Y. Matsuzaki ${ }^{2}$,

H. Mutoh ${ }^{2}$, N. Tanaka ${ }^{2}$

' Division of Gastroenterology,

Department of Internal Medicine,

Mito Kyodo General Hospital,

Ibaraki, Japan

${ }^{2}$ Division of Gastroenterology,

Department of Internal Medicine,

Institute of Clinical Medicine,

University of Tsukuba, Ibaraki, Japan

\section{References}

1. Kasahara $\mathrm{Y}$, Tanaka S, Nishino $\mathrm{M}$ et al. Intestinal involvement in Behçet's disease: review of 136 surgical cases in the Japanese literature. Dis Colon Rectum 1981; 24: 103-6.

2. Brodie TE, Ochsner JL. Behçet's syndrome with ulcerative oesophagitis: report of the first case. Thorax 1973; 28: $637-40$

3. Mori S, Yoshihara A, Kawamura $\mathrm{H}$ et al. Esophageal involvement in Behçet's disease. Am J Gastroenterol 1983; 78: 548-53.
4. Yashiro K, Nagasako K, Hasegawa K et al. Esophageal lesions in intestinal Behçet's disease. Endoscopy 1986; 19: $57-60$.

5. Shimizu T, Ehrlich GE, Inaba G et al. Behçet's disease (Behçet's syndrome). Semin Arthritis Rheum 1979; 8: 223 60.
Corresponding Author

Kazuto Ikezawa, M.D.

Division of Gastroenterology

Department of Internal Medicine

Mito Kyodo General Hospital

3-2-7 Miya Chou, Mito 310

Ibaraki, Japan

Fax: +81-29-221-5137 